\title{
AN INTEGRATIVE ProJeCT IN MiCROPROCESSOR INTERfACES
}

\author{
Allyson Giannikouris and Chris Rennick \\ University of Waterloo \\ Allyson.giannikouris@uwaterloo.ca,crennick@uwaterloo.ca
}

\begin{abstract}
In the third-year microprocessors course given to Mechatronics Engineering students at the University of Waterloo, the lab studies have been redesigned as a scaffolded project. The project aims to provide a more authentic learning opportunity that integrates concepts from the concurrent courses, as well as prior courses. The project was carefully designed to provide some student autonomy while ensuring competence can be achieved by students with a broad range of initial skill levels through the completion of authentic tasks. The impacts of the revised project on student learning were measured using pre- and postproject surveys, course grades and course critiques. Despite significant challenges that were encountered during the first two offerings, the results show that students perceived an increased competence in several key skills, and an increase was seen in overall course satisfaction.
\end{abstract}

Keywords: Experiential Learning, Student Engagement, Knowledge Integration

\section{INTRODUCTION}

Active learning can take many forms: it can take place in, or outside the lecture hall, can include peer collaboration or be independent in nature, it can involve the instructor, or just the students; but in whatever form it takes, it has been widely shown to improve learning outcomes in STEM fields [1]. Since its inception, Engineering has always contained active learning typically in the form of labs or field exercises. More recently, project-based learning has become a popular means to increase the level of active learning in Engineering classrooms (a search of the ASEE conference repository for "project-based learning" reveals over 4500 papers describing its use [2]).

While project-based learning and problem-based learning are not quite the same thing, they do have many elements in common. Prince [1], in summarizing the work of others, outlined several features that led to positive outcomes in problem-based learning including placing students in small groups, and using cooperative learning structures. Formal instruction in problem-solving has also shown to improve learning outcomes from problem-based learning. While including formal problem-solving instruction may be difficult for many instructors (due to time constraints, etc), the "cognitive apprenticeship" model described by Collins, Brown, and Newman may provide an alternative [3] instructional model. Applying cognitive apprenticeship teaching methods requires an instructor to "bring these tacit [problem-solving] processes into the open, where students can observe, enact, and practice them with help from the teacher and from other students". Cognitive apprenticeship methods also require that the learning be situated in the contexts of its use.

\subsection{Self-Determination Theory}

Self-Determination Theory (SDT) describes three psychological needs to drive self-motivation (i.e. intrinsic motivation) and growth tendencies: the need for competence, relatedness, and autonomy [4]. In this theory, the need for competence is described as the feeling that one is able to successfully complete a task (i.e. self-efficacy); the need for relatedness is the sense of belonging to the context, as well as the sense of feeling connected to others; and the need for autonomy is the feeling that the requirement to complete a task is self-driven (i.e. of the students' own volition) and self-endorsed.

Niemiec and Ryan in their article on applying SDT to the classroom [5], argued that intrinsic motivation in students relied on the needs for autonomy and competence. Thus, a task should lead to higher levels of intrinsic motivation in students if they feel they are in control of their own learning (autonomy), and if they feel they are able to complete the task (competence). Niemiec and Ryan also argued that internalization of learning was enhanced when students' need for relatedness was met by the learning environment. They went on to explain that this was personified in the classroom by an instructor that shows they care about their students learning, by anchoring an experience in a context that students feel a part of - and see the relevance of - and by providing opportunities for students to connect with their peers.

Summarizing the results from Prince [1], and from Niemiec and Ryan [5], a high-impact learning experience that leads to intrinsically motivated students will be active and collaborative, and grounded in a realistic and relevant context for students. This activity should provide students with a sense of autonomy, and they should be supported by the instructor to develop their self-efficacy and problemsolving skills. 


\subsection{MTE 325}

Mechatronics Engineering (MTE) at the University of Waterloo (Waterloo) is a multi-disciplinary program that includes courses from Mechanical Engineering, Electrical and Computer Engineering, and Systems Design Engineering. In the first semester of third year (3A), MTE students take 5 courses: Introduction to Thermodynamics and Heat Transfer, Kinematics and Dynamics of Machines, Actuators and Power Electronics, Microprocessor Systems and Interfacing, and Systems Models 1. By this point in their undergraduate careers, students have completed 3 to 4 of their mandatory co-op work terms (approximately 12 -16 months of work experience), leading to a broad range of skill levels and diverse experiences.

Microprocessor Systems and Interfacing (MTE 325) is offered twice a year, to approximately 200 students in total. Students typically find the course difficult as it requires them to recall knowledge from prior courses (digital logic, operating systems) and integrate it in new ways. Additionally, students have a wide range of initial skill levels (due to varying co-op and extracurricular experiences), adding to the instructional challenge. This is the last core course in the computer systems topic thread, meaning it is the last chance before students start their capstone projects to ensure competence with a set of skills that are central to the program.

To address student concerns that the core courses and projects in $3 \mathrm{~A}$ were disjointed and irrelevant, a new project was developed to replace existing laboratory studies in MTE 325. This paper will focus on the development of an integrative project - aligned with the principles of SDT that replaced existing course labs in MTE 325, the implementation challenges encountered, and the impacts that have been measured so far. This paper has six sections: section two describes the motivation behind this redevelopment, section three describes the first two offerings of the new integrative project, section four describes the impact of these changes, the final sections are future improvements, and conclusions.

\section{MOTIVATION}

Starting in 2018, changes were made to the existing laboratory studies in MTE 325, based on three major concerns:

1. The labs were no longer relatable to students as they had seen few revisions over a 15 year span.

2. Revisions that were done had removed components relevant to the course Intended Learning Outcomes (ILOs).

3. This course was originally designed for students in another department (Electrical and Computer Engineering, or ECE), resulting in labs that were never a good a fit for MTE.
Prior to the changes described in this paper, the first lab asked students to conduct some experiments using the softcore processor on a field programmable gate array (FPGA) board to compare the latency of interrupts and polling. While the underlying principles of the experiments and the expected observations were valuable, the implementation was problematic as the MTE students had no prior experience with FPGA tools. In contrast, ECE students (where this course was adapted from) had used the tools in a previous course.

The second lab asked students to code an audio player that behaved like a CD player on an FPGA board. This exercise was at least 15 years old and had only undergone minor revisions, some of which had resulted in the removal of the aspects of the lab that were more relevant to the ILOs of the course. Student feedback from the MTE students during the 2017 offerings indicated the lab was outdated (some had never used a CD player!) and that it was not relevant to their program. Additionally, students often struggled with the lab due to weaker programming skills and less familiarity with the FPGA tools compared to their ECE counterparts, which led to more student time being used than intended. Clearly redevelopment of these labs was required, which created an opportunity to implement significant active learning in a way that is less prescriptive than a typical lab, and that is more grounded in the real experiences MTE students face in the workplace.

\section{IMPLEMENTATION}

Instead of simply updating the labs with new exercises, the course instructor, with assistance from the Engineering IDEAs Clinic, developed a project that connects to what is taught in all five $3 \mathrm{~A}$ courses. Significant work has been done on the integration of courses within the Engineering faculty at Waterloo [6] [7] [8] [9] over the last several years. Compared to prior work at Waterloo, this project redesign was different as it takes place not in a design course, but in a complex, third year engineering science course with a very steep learning curve. This new project was originally conceived as one that would integrate concepts from all five courses (Al-Holou et al [10] would characterize this implementation as separate courses with fixed-time allocation and an integrated design project), and allow the same platform to be used and explored in different ways by each course.

While the project hardware was designed with the flexibility (and scope) required to achieve this integration, the idea of integrating the project across all five courses on a short timeline quickly became impractical: having one project that supported all courses was ruled out early on due to the logistical issues of support and marking. There were also concerns that while these are required courses for the MTE students, MTE 325 in particular is often taken as an elective by students in other engineering programs. Instructor turnover with the other courses also resulted in a

CEEA19; Paper 034

University of Ottawa; June 9 - 12, 2019 
decrease in interest in participation in the project. Ultimately, the decision was made to house the project solely in MTE 325 while continuing to make connections to the other courses where possible.

As the new project took shape, it was designed based on best-practice principles including:

- meeting students' needs for competence, relatedness, and autonomy [5];

- $\quad$ the need to avoid cognitive overload [11] [12];

- $\quad$ students need practice with integrating component skills [11];

- developing students' procedural knowledge, or "know-how" [13] is critical for their future success as engineers.

There were also a number of other considerations when the project was designed. The project:

- must be reasonable for an average student to complete in roughly 30 hours;

- should have flexibility for adaptation based on the skill level of group members;

- $\quad$ should include a variety of deliverable types;

- long term, must use the human resources already allocated to this course;

- $\quad$ should be based on a common platform that can be used in multiple terms to reduce the cognitive load of learning new tools and systems.

The result was a project housed in MTE 325, with links and hands-on exposure, both directly and indirectly, to what they learned in their other courses. For example, they used stepper motors to drive the machine, which they learned about in power electronics. It also exposed them to machine elements they will study in the second semester of third year, such as belt drives and lead screws.

The characteristics of high impact practices identified by Kuh [14] also drove the project design, in particular

- $\quad$ set clear, performance expectations at appropriately high levels;

- $\quad$ encourage students to invest significant and meaningful time and effort on authentic, complex tasks over an extended period of time;
- $\quad$ provide frequent, timely and constructive feedback;

- $\quad$ provide opportunities to discover relevance of learning through real-world applications.

The initial project design was completed during the fall 2017 term. The design work was divided into two categories: the physical machines/hardware and the tasks students were asked to complete.

\subsection{Hardware Development}

Once a clear picture for the machine requirements had developed, the Ideas Clinic began designing the platform. A two-axis machine was chosen due it its ubiquitous nature in modern machines and the flexibility of its implementation. To leverage this flexibility, to increase the student exposure to industrial grade equipment, and to increase the level of student autonomy present in the project, multiple standard designs were conceived. Two designs were completed for the first offering, with a third design added later. The first two designs were based on lead screws and pulleys respectively, with the third design being a vertical two-axis machine as shown in Figure 1. Misumi components were chosen to form the basis for the machines as they are industry grade components the MTE students are likely to see in the workplace. They are also rugged enough to last through many years of student (mis)use. The STM32F4 ARM microprocessor development board was chosen for its compatibility with both Arduino shields and proprietary shields, ensuring flexibility for future project expansions or equipment reuse in other courses. The integrated development environment (IDE) was selected for compatibility with the chosen development board, as well as for familiarity to the students as they use it in a previous course. Choosing a familiar tool should remove some of the cognitive load of competing an embedded system project with minimal experience.

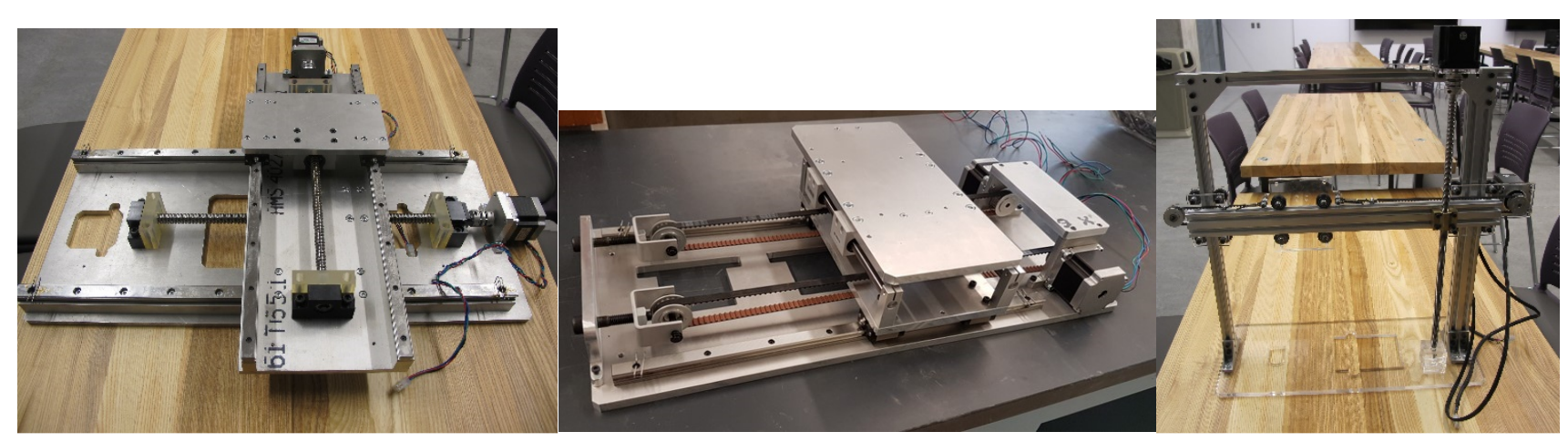

Figure 1: Three two-axis machine designs. Left: lead screw based, middle: pulley based, right: vertical machine

CEEA19; Paper 034

University of Ottawa; June 9 - 12, 2019

-3 of $8-$ 


\subsection{Student Project Tasks}

Seven Intended Learning Outcomes (ILOs) were developed for the project:

1. implement and compare interrupts and polling

2. configure and use parallel ports in an embedded system

3. use serial interfaces in an embedded system

4. configure and characterize the behaviour of an analog to digital converter (ADC)

5. characterize the behaviour of DC motors in an embedded system

6. use industry grade tools and equipment to configure and debug an embedded system

7. write $\mathrm{C}$ code that follows generally accepted industry standards for structure and formatting

Some of ILOs map directly to specific project tasks, while others are necessary sub-steps. From the ILOs, a final set of five tasks was developed. These tasks are:

1. configure and use an ADC

2. connect and use limit switches to maintain safe machine operation

3. configure and use stepper motors to control machine movement

4. decode serial protocols

5. document the system configuration

While completing all of the above tasks, students were also asked to keep notes on the design decisions they made, any problems they encountered and the steps taken to resolve them, as well as the procedures and results for any experiments they conducted. While students practice writing formal reports throughout their engineering education, they rarely have the opportunity to practice keeping a log book and receiving feedback on their notes. This is a common task in industry, making it a valuable, and authentic skill to practice.

The five project tasks were mostly independent of each other and were assessed through demonstrations and/or written submissions. The demonstrations allowed students to present the work they did and gave the teaching team the opportunity to ask questions to determine the initial skill level of the group, then adjust the demonstration expectations within reason. Students were guided during these demonstrations to not only discuss what they did, but to reflect on what they learned and how they can improve. Those improvements might be related to more general skills like documenting their experimental procedures and presenting the results, or to embedded system specific skills such following coding best practices.

Immediate feedback was provided to students, which they could act on while completing the remaining tasks. Due to the varied skill levels, and the inherent challenges of working with hardware, there was an "escape hatch" where a group that struggled or could not achieve full functionality could still get a good grade by showing insight into the problems they experienced and demonstrating what they have learned through "failure". This escape hatch was not made explicit to students, but rather was applied at the instructor's discretion by making adjustments to deliverables where appropriate.

\subsection{First Offering}

For the winter 2018 offering, only the post midterm lab (the audio player) was replaced with the revised project in order to ease the course transition to the new project.

There were some logistical challenges encountered with the project launch. Despite ordering the parts to build 10 each of two of the machine designs in the fall, some of the crucial parts were on backorder for many months. This made it impossible to build the screw-driven machines, and left our pulley-based machines with only one axis of motion. As a result, few machines were available for students and they no longer had any choice as to the machine type. It also reduced the complexity of numerous project tasks.

For this offering, students formed their own groups of four due to the limited number of machines available, and were not restricted to members of the same lab session. Students were asked to only attend one scheduled lab session per lab week, but that was not always respected which led to some overcrowding issues in the lab. TAs were available for help during the scheduled sessions, and the instructor was present when possible. Students' access to the lab was limited to ensure the teaching team could monitor the problems students were experiencing and make adjustments, or provide additional resources as necessary to ensure time was being spent working towards the ILOs (and not stuck on problems that are outside the scope of the course).

It became clear that students struggled to achieve even basic functionality, so two additional evening sessions were offered where the lab was open and the instructor was available to help students. The instructor observed that students did not understand how to use the documentation available for the microprocessors they were using, and that they were unsure how to get interrupts working on the microprocessor as their prior experience with this task (during lab 1) used a different platform. Additionally, students were not making good use of the tools available to them, such as the debugger, which they should have been familiar with from a previous course.

This project was designed to move away from the procedural nature of previous labs and gave students more choice and flexibility in how they accomplished the tasks. As a result, the level of expertise required of the teaching assistants (TAs) who supported the course increased. Due to changes outside of the instructor's control, the course TAs did not have the time to properly prepare, and one did not have strong skills in the project area. As a result, the level of support given to students in the lab was lower than

CEEA19; Paper 034

University of Ottawa; June $9-12,2019 \quad-4$ of $8-$ 
desired. Many students noted in their post-project feedback that they did not feel an adequate level of help was available, and that this was a significant frustration for them with a negative impact on their experience.

To further develop the project, the authors participated in the Waterloo Assessment Institute in April 2018. This was a two-day workshop with a focus on assessment and outcome alignment, with feedback from peers as well as the Center for Teaching Excellence at the University of Waterloo. This experience, combined with the instructor observations and student feedback during the pilot offering, resulted in changes to the project, and a reworking of the assessment methods.

\subsection{Second Offering}

In the spring 2018 term, all of the former lab studies were replaced with exercises that formed the scaffolded project. This full launch had originally been planned for winter 2019, but had to be accelerated due to a change in resource availability. Having students work solely on the two-axis platform provided an opportunity to address some of the skills gaps that had been observed the term before by introducing the project platform earlier in the course.

In place of the old first lab, two additional scheduled sessions were added before midterms. The first session addressed some of the issues around tool setup and use. There were no marks associated with this session. The teaching team verified by the end of this session that every group had the following functionality up and running:

- functional hardware and software including:

o microprocessor and motor controllers;

o development environment;

o serial terminal.

- $\quad$ ability to find unused pins;

- ability to read and write to a pin;

- ability to use basic functionality of the debugger.

The second session replaced the previous polling and interrupts lab. Since the intended outcome of this lab is very well aligned with course outcomes, the core ideas were kept. Students were still asked to perform experiments to compare the response times of polling and interrupts to external stimulation, but it was completed using the same microprocessor as the project (plus a signal generator and an oscilloscope). For MTE students, it is far more likely that they will need to use this equipment in the workplace than an FPGA, making the experiments more authentic and relevant for them. It was also an excellent opportunity to reinforce the skills they acquired in first year on how to properly use these pieces of lab equipment that they may not have used since. The experiments they are asked to conduct were streamlined so that most students could complete them and gather the necessary data within one 3-hour lab session. Students then submitted a short write-up documenting the experiments they performed and interpreted the results.
The second stage of the project started the week before midterms and was structured similarly to the winter 2018 offering, however the assessments of the tasks were revised with more detailed rubrics and redistributed weightings. These revisions were driven by student feedback as well as participation in the Waterloo Assessment Institute. Figure 2 below outlines the course content present in each stage of the project.

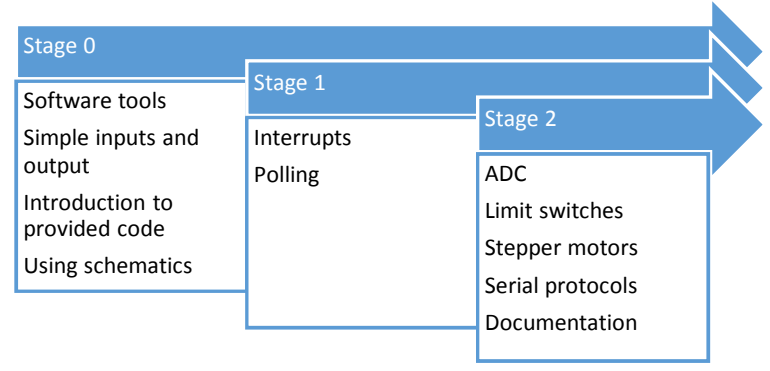

Figure 2: Elements of the complete scaffolded project

Unfortunately, some machine parts were still on backorder, so students were once again restricted to only one type of machine, though they were now fully functional. Students were still in groups of 4 and chose their groups, but they were required to be with students from the same lab section. This alleviated the overcrowding issues in the lab as it ensured there were fewer groups present than machines. Machines were not assigned, although students tended to work on the same one each time. When students did change machines, there were sometimes issues with slightly different operating characteristics that caused problems if they tuned their code to a certain setup. Strong TA support also continued to be a challenge during this offering.

Due to the compounding of all the issues encountered, some tasks were reverted to single axis, similar to what had been used the term before. Bonus marks were offered for implementing full two-axis functionality. An additional bonus deliverable was also added that allowed students to document and discuss a bug they had spent a minimum of 2 hours working to solve. This provided a mechanism to recover some marks if full functionality was not achieved in some tasks by demonstrating problem solving skills and reflection on their learning.

\section{IMPACT ON STUDENT LEARNING}

In order to determine the impact on student learning and attitudes, several types of data were collected: a survey was offered to the 2017 students; pre- and post-project surveys were offered to students during both 2018 offerings; instructor observations and informal feedback were noted as the project was offered; and course critique data was examined (MTE 325 has been taught by the same instructor since 2017). 
The pre- and post-project surveys for the 2018 offerings had a mix of open-ended and Likert scale questions. For the winter 2018 offering there were 105 students enrolled with 102 and 93 students completing the pre- and postproject surveys, respectively. For the spring 2018 offering there were 81 students enrolled with 51 and 48 students completing the pre- and post-project surveys, respectively. One of the Likert questions asked students to rate their perceived level of expertise with a set of embedded system skills required in the project including the following:

- configure and use an ADC on a microprocessor;

- identify tasks and sub-tasks necessary to complete an embedded system-based project;

- use low level device drivers to interact with peripherals on a microprocessor;

- use a schematic to find connections on a PCB.

For each skill they were given the options of no skill/beginner, intermediate, advanced and expert. The results are summarized in Figure 3. A decrease in the number of students that rank themselves as no skill/beginner at the beginning of the term, with corresponding increases at the more advanced levels was expected. This has been the case, $(36 \%$ reduction in winter $2018,30 \%$ reduction in spring 2018 in the number of students at the beginner level for using an ADC) with varying degrees of improvement seen across the skills. The decrease in the number of students ranking themselves at the expert level in some skills was likely due to students overestimating their competence at start of term and realizing they are not as experienced as they initially perceived themselves to be.

Given the typical background of an MTE student, it is not surprising that very few perceive themselves as experts, but it was unexpected that no one in the spring 2018 offering perceived themselves as such for several of these skills. The data also show that for several skills, greater improvements overall were seen in the winter 2018 offering, with more students increasing their skill level or more students increasing to the advanced level (configure an ADC, identify tasks and use drivers). This was likely due to the lower overall interest of the spring class (as perceived by the course instructor) in embedded systems in general as well as some of the logistical issues faced during this offering. One exception was the higher percentage of students who perceived improvement in their ability to use schematics in the spring 2018 term. This was likely due to the identification of a skill gap in using such tools during the winter 2018 offering, which was specifically targeted in project material revisions in spring 2018.

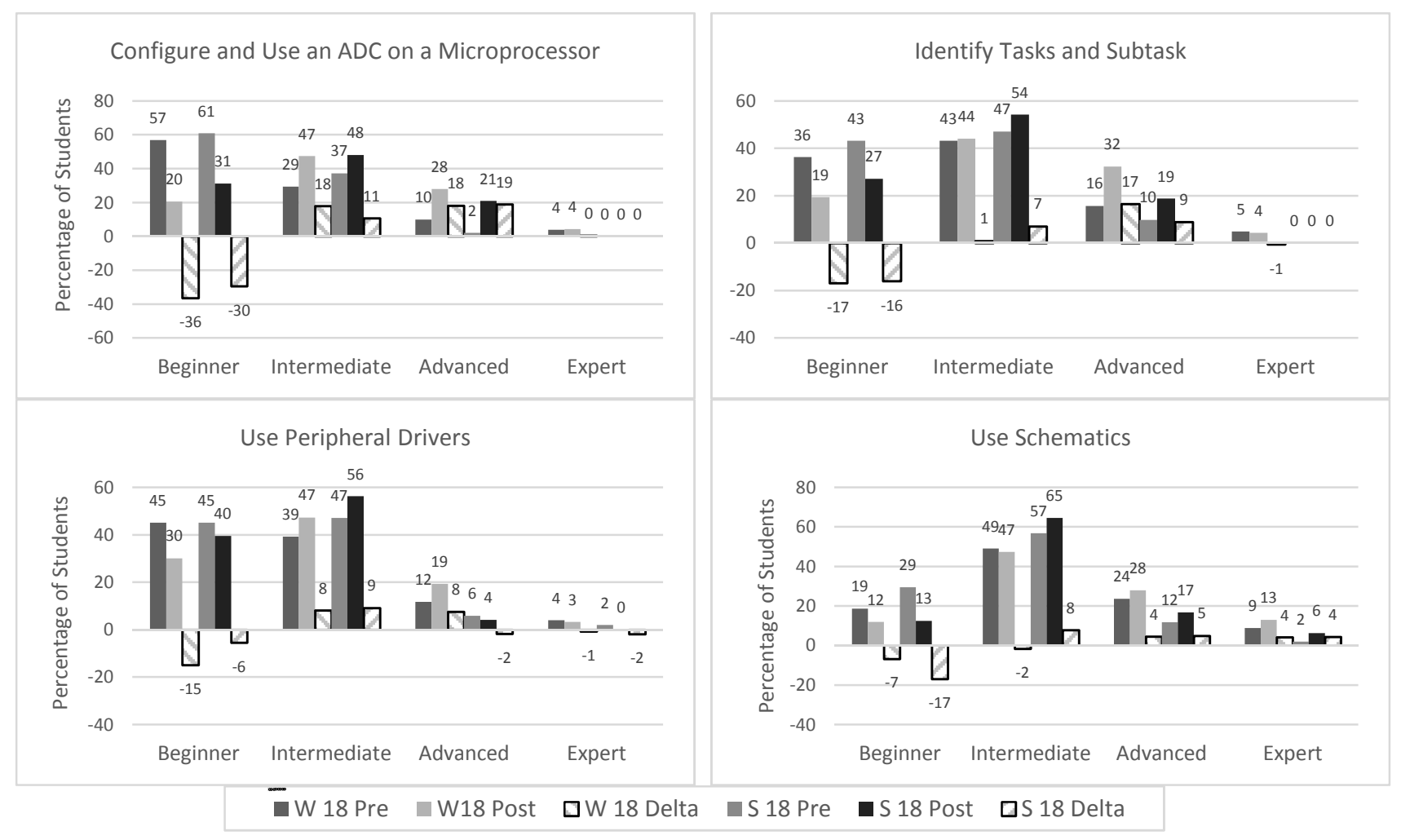

Figure 3: Summary of winter 2018 and spring 2018 pre and post project perceived student skill levels 
Despite the significant support and logistical challenges that were encountered during the first two offerings of the project, student perception of the course overall as measured by Waterloo's course critiques showed improvement, as shown in Table 1. No major changes were made to the lectures or tutorials during this time, so improvement to overall course perception can be attributed predominantly to the project.

Table 1: Overall Course Scores (out of 100) for MTE 325

\begin{tabular}{|c|c|c|c|}
\hline $\begin{array}{c}\text { Winter } \\
\mathbf{2 0 1 7}\end{array}$ & $\begin{array}{c}\text { Spring } \\
\mathbf{2 0 1 7}\end{array}$ & $\begin{array}{c}\text { Winter } \\
\mathbf{2 0 1 8}\end{array}$ & $\begin{array}{c}\text { Spring } \\
\mathbf{2 0 1 8}\end{array}$ \\
\hline 64 & 68 & 76 & 75 \\
\hline
\end{tabular}

\subsection{Impact on Student Grades}

Student averages on midterm exams, final exams, labs or projects, and overall average were compared for the 4 offerings of the course in 2017 and 2018. No significant difference was seen in the midterm or final exam averages. A small increase was seen in the average project grade compared to the previous labs, and this led to a small increase $(\sim 3 \%)$ of average final grade. Due to the drastic change in project vs. lab requirements and evaluation methods, it is not an accurate comparison and the difference can be disregarded. What is notable is that while no significant change was seen in midterm or final exam grades, there may still have been an increase in student learning as the topics tested on the midterm and final target different learning outcomes than those developed in the course project. Maintaining the exam averages is an encouraging sign that the project has not negatively impacted the course overall. These findings are also in line with Prince's findings that problem-based learning is not likely to lead to improvements in test scores, but does improve student attitudes [1].

\subsection{Instructor Perspective}

The second offering of the project in the spring 2018 term presented several unexpected challenges. Once again, there were issues with finding TAs that had the proper background. The instructor also had a scheduling conflict that prevented attendance during the first offering of each lab session, making it difficult to calibrate expectations for deliverables and assist with training the TAs. This had a negative impact on student's experiences as they did not feel that they were able to get help when they were stuck, and that their time was being wasted as a result. The lack of consistent expectations between TAs was also a problem when it came to grading.

Students enrolled in the spring 2018 term also rated themselves as having lower overall perceived skill levels at the beginning of the project. For example, in the winter offering, $9 \%$ of students rated their pre-project skill level for using a schematic to find pins and connections on a
PCB as expert, while only $2 \%$ said the same in spring 2018. On several of the skills, there were no members of the spring 2018 class who perceived themselves as experts initially. There was also less overall interest within the class in embedded systems than the previous term. The impact of this was very apparent to the instructor as a lower level of student engagement with the project, more resistance, and complaints that what they were being asked to do was too difficult. It was also apparent that there was a lack of peer support within the class helping each other to solve problems and complete project objectives outside the scheduled lab sessions, leading to a lack of preparation and less efficient use of the supported time they did have.

Despite the many unanticipated staffing and equipment challenges, moving to the scaffolded project can be considered a successful improvement to the course. Designing and implementing this project required significantly more time and effort than traditional labs, but the ability to adapt to student skill levels and interests, and offer a better learning experience made it worthwhile.

Despite the positive impacts of the project, having the instructor present during all lab sessions is not sustainable in the long term. Lab instructors in the department are able to provide support for equipment maintenance and some TA training, but they are not able to attend and support all lab sessions. As such, it is critical that a TA pool be built up so that there is always at least one TA in the lab who has provided support for the project previously. The nature of the project means that while new TAs can prepare by completing the tasks for themselves, they lack the handson debugging expertise that can only be developed by spending time in the lab with students. Building this strong TA pool is crucial to the long-term sustainability of the project as it will reduce the load on the instructor while ensuring the student experience is not compromised. Giving students the support to achieve competence with timely feedback on their progress is essential to fostering autonomy and intrinsic motivation [5].

\section{FUTURE IMPROVEMENTS}

As of this writing of this paper, the third offering of the course is currently underway for the winter 2019 term. Once again, changes were made to address student feedback and some of the challenges that were faced in previous terms. The instructions and supporting documents for the first two lab sessions have been combined for clarity as students found it difficult to easily locate the information they needed. Clarifications of expectations and additional background information were also added based on common challenges students faced the previous term.

For this offering we were fortunate enough to find and hire TAs with extensive embedded systems experience. Despite being new to the course, they quickly showed themselves to be very capable in helping students debug their code and ensuring students aren't struggling with

CEEA19; Paper 034

University of Ottawa; June 9 - 12, 2019 
problems that are outside the scope of the project. The instructor's schedule was also improved to allow attendance at all sessions, providing additional support to both the students and the TAs.

Lastly, now that more equipment is functional, group sizes have been reduced to 2-3 students. This gives each student more contact time with the machines and improve individual learning. Students now have the choice of using any of the three different machine types, and are assigned to a particular machine for the term. This should address some of the issues seen in the past with inconsistent machine behaviour, and strengthens student autonomy in the project.

\section{CONCLUSION}

The need to overhaul the lab component of a third year course in Microprocessors and Interfaces at the University of Waterloo (MTE 325) presented an opportunity to replace an outdated and ill-aligned course component with an authentic, integrated learning opportunity. The new project satisfies student needs as defined by SelfDetermination Theory: the needs for competence, relatedness, and autonomy. The project builds on concepts seen in prior courses, and connects to the concurrent courses whenever possible. These concepts are not always explicitly graded, but the connections are there nonetheless.

There were multiple logistical issues encountered during the first two offerings, including hardware on backorder and difficulty hiring knowledgeable TAs to support the course. Despite this, there was still an improvement in students' perceived skill levels with the skills targeted by the project. Overall student satisfaction with the course also increased.

From the instructor perspective, the project required more effort to develop than traditional labs, as well as a greater level of ongoing support. That said, the effort was worth it for the improvement in alignment and increased student satisfaction with the course. As the project becomes more mature and a robust support team is developed, the additional time required for support is expected to decrease. Despite having little impact on course grades, the increase in student engagement with the project through an authentic learning opportunity has been successful at providing some integration with concurrent courses and improving student learning.

\section{ACKNOWLEDGEMENTS}

Thank you to the IDEAs Clinic and Prof. Sanjeev Bedi at the University of Waterloo for their support throughout this initiative.

\section{REFERENCES}

[1] M. Prince, "Does Active Learning Work? A Review of the Research," Journal of Engineering Education, vol. 93, no. 3, pp. 223-231, 2004.

[2] ASEE, "PEER," [Online]. Available: https://peer.asee.org/?q=projectbased+learning\&commit=Search. [Accessed 1 March 2019].

[3] A. Collins, J. S. Brown and S. E. Newman, "Cognitive Apprenticeship: Teaching the Craft of Reading, Writing, and Mathematics," University of Illinois at UrbanaChampaign, Urbana and Champaign, 1987.

[4] R. M. Ryan and E. L. Deci, "Self-Determination Theory and the Facilitation of Intrinsic Motivation, Social Development, and Well-Being," American Psychologist, vol. 55 , no. 1 , pp. $68-78,2000$.

[5] C. P. Niemiec and R. M. Ryan, "Autonomy, competence, and relatedness in the classroom: Applying selfdetermination theory to educational practice," Theory and Research in Education, vol. 7, no. 2, pp. 133-144, 2009.

[6] S. Bedi, C. Hulls, C. Rennick, M. Robinson and W. Melek, "Design of an Introductory Engineering Design and Communication Course Which Integrates First Semester Courses," in CEEA Annual Conference, Toronto, 2017.

[7] C. Hulls, C. Rennick, S. Bedi, M. Robinson and W. Melek, "The Use of an Open-Ended Project to Improve the Student Experience in First Year Engineering," in Canadian Engineering Education Association Conference, Hamilton, 2015.

[8] C. Hulls, C. Rennick, M. Robinson, W. Melek and S. Bedi, "Integrative Activities for First-Year Engineering Students - Fuel Cell Cars as a Linking Project Between Chemistry, Mechatronics Concepts and Programming," in CEEA Annual Conference, Canmore, 2014.

[9] C. Rennick, C. Hulls, A. Milne, D. Wright, E. Li and S. Bedi, "Engineering Design Days: Engaging Students with Authentic Problem-Solving in an Academic Hackathon," in ASEE Annual Conference, Salt Lake City, Utah (submitted), 2018.

[10] N. Al-Holou, N. Bilgutay, C. Corleto, J. T. Demel, R. Felder, K. Frair, J. E. Froyd, M. Hoit, J. Morgan and D. L. Wells, "First-Year Integrated Curricula Across Engineering Education Coalitions," in Frontiers in Education Conference, Tempe, 1998.

[11] S. Ambrose, M. W. Bridges, M. DiPietro, M. C. Lovett, M. K. Norman and R. E. Mayer, in How Learning Works: Seven Research-Based Principles for Smart Teaching, San Francisco, John Wiley \& Sons, Inc, 2010, pp. 103-120.

[12] M. Svinicki, Learning and Motivation in the Postsecondary Classroom, San Francisco: Jossey-Bass, 2004.

[13] P. Frise, G. Rohrauer, B. Minaker and W. Altenhof, "Identifying the Design Engineering Body of Knowledge," in International Conference on Engineering Design (ICED), Stockholm, 2003.

[14] G. Kuh, High-Impact Educational Practices: What They Are, Who Has Access to Them, and Why They Matter, Washington: AAC\&U, 2008. 